\title{
Paideusis
}

\section{Do We Need Theories of Education?}

\section{John Wilson and Barbara Cowell}

Volume 1, Number 2, 1988

URI: https://id.erudit.org/iderudit/1073423ar

DOI: https://doi.org/10.7202/1073423ar

See table of contents

Publisher(s)

Canadian Philosophy of Education Society

ISSN

0838-4517 (print)

1916-0348 (digital)

Explore this journal

Cite this article

Wilson, J. \& Cowell, B. (1988). Do We Need Theories of Education? Paideusis, 1(2), 2-11. https://doi.org/10.7202/1073423ar

This document is protected by copyright law. Use of the services of Erudit (including reproduction) is subject to its terms and conditions, which can be viewed online.

https://apropos.erudit.org/en/users/policy-on-use/
This article is disseminated and preserved by Érudit.

Érudit is a non-profit inter-university consortium of the Université de Montréal, Université Laval, and the Université du Québec à Montréal. Its mission is to promote and disseminate research.

https://www.erudit.org/en/ 


\section{Do We Need Theories of Education?}

\section{John Wilson, Department of Educational Studies, Oxford University \\ Barbara Cowell, Warborough Trust, Oxford University}

Not only philosophers of education but almost anyone who has thought about education at all seriously will have bumped into a genre of writing for which "theories of education" will serve as an initial, if deeply obscure, description. We mean, for instance, the writings of people like Plato, Rousseau, Montaigne, Dewey, and many others. Consideration of these writings still forms a large part, not only of philosophy of education in a narrower sense, but of our general thought abut education; and not only our general thought, but also our practice in schools and elsewhere. The question arises of whether we actually need such theories of education, which, of course, necessitates the prior question or questions of just what these theories are supposed to be or to do, and how we are to evaluate them.

We say "the question arises," but perhaps the first thing that ought to be said is that, for most people most of the time, the question is not actually raised at all. It is, largely, still taken for granted not only that these theories ought to form the subject-matter of debate, but also (and worse) that it is clear what the theories are about, what their logical status is. So one or both of two things happen. Either (a) a person has some kind of objective interest in the history of ideas (cultural history) perhaps - and simply considers these theories in a historical or sociological way, reflecting on their prevalence and influence, or trying to elucidate their basic ideas and social connections; and/or, (b) he is interested in evaluating them, makes some attempt to improve on them or synthesize them, or signs himself (herself) up as a representative of one or another of them, or an opponent. Neither of these faces the question (c), which we are concerned with here, of what the function, worth or force of such theories can reasonably be taken to be.

This position is not peculiar to education. If we consider, for instance, the theories (if "theories" is the right word) of Marx or Freud, we can of course confine our attention to (a) and/or (b) above. We can regard these authors as propounding some sort of "general ideas," about (say) the importance of economics or social class or sexuality or whatever, and (a) trace their influence in history and society, and/or (b) show ourselves more or else in sympathy with them, or criticize particular elements in them. But (we suggest) any 
serious and genuinely open-minded person will want to know-putting it briefly-what sort of talk it is that he actually finds in this literature. How is he (she) to receive it-as a kind of science, or set of empirical facts, or a kind of mythology, or propaganda or ideology (what that is, or what? How, especially, is he to determine its worth? How is it to be verified (if the idea of "verification" is to place here)?

It is important to see that these problems are not dispelled even if we try to confine ourselves to (a), perhaps with the idea that so long as we eschew value-judgments and stick to pure sociological or historical or some other kind of fact we can avoid most of our difficulties. There are more things wrong with this idea than we wish to discuss here; but the main point is perhaps that in order to make it useful to trace the history or sociology of $X$ we must have good grounds for thinking (i) that we know what $X$ actually is, and (ii) that $X$ represents an important category in human life and thought. Neither of these is at all obvious in most cases. We play, for instance, with "general ideas" which we represent by categoryterms such as "left," "right," "democratic" or "totalitarian," in politics or "progressive" and "traditional" in education. But it is not clear either (i) just what these categories really represent, what the substance behind the category-terms actually is, or (ii) whether these, rather than others, are in fact important or significant categories. The whole business of fruitful categorization, so important, for example, the history of zoology and other natural sciences, is still more important-and more difficult-in sociology and the history of ideas. (We dimly grasp and worry about this when, for instance, we come to see that extremes of political behaviour of both "left" and "right" show important similarities.)

In the high and balmy days of linguistic analysis, many philosophers took a short and brutal way with these questions. There were, they said, basically only two categories of respectable discourse: on the one hand, talk about concepts and their logic, about the meanings of words and their logical implications and, on the other, empirical talk. Merits of the former were verified by close attention to linguistic usage and pure logic and, in the case of the latter, by hard experiment and empirical research. One may doubt historically whether many philosophers were quite so brutal in practice as we have just represented them; but at least they threw down an important challenge, roughly of the form, "Here, at least, are two respectable and clear kinds of discourse which we know how to handle. Now, if someone wishes to talk in some other way, the onus is on him to make the logical status of his talk clear to his readers." That challenge, we think, still stands. 1 
It is no answer to the challenge to say that these theories, or "general ideas," have been and still are influential. All sorts of ideas have influenced human beings, many of them not respectable at all by any criteria. It does nothing for the respectability of Nazi discourse about Aryan blood to say that it was influential, or changed people's minds, or altered human consciousness, or whatever. The main point is that the status of the talk was and is unclear. So far as this example is concerned, we may reasonably dismiss it as a fantasy, some kind of obsession or delusion that emerged (as fantasies always do) in discourse which was systematically incoherent. People did indeed--and we shall return to this point-feel like saying such things: but, pro tanto, this goes no way towards satisfying any criteria of merit, or value, or even clarity. And, again, even if our sole interest is that of the sociologist or historian, we are still left with the problem of adequately describing and making sense of Nazi philosophy before making confident pronouncements about its cultural effects and influence.

At the same time it will not do to dismiss theories of education out of hand. We apply too sharp an axe to discourse if we outlaw certain kinds of it before fully understanding what those kinds actually are: this would be to repeat the grotesque mistake of early logical positivist philosophers who went so far as to describe moral and valuative discourse as "meaningless." Very few cases of human discourse are meaningless: indeed it is hard to think of any cases except those deliberately designed to be so, such as the nonsense poems of Lewis Carroll. Like benevolent psychiatrists, we have somehow to tease out the underlying purposes of educational theories, the basic emotions and thoughts on which the (often very elaborate) superstructures of the discourse rest. Even the wildest and most odious cases, like that of the Nazis, can be seen and interpreted as trying to say something that might, under guidance, be seen as worth saying (perhaps, in this example, something about notions like purity, identity and self-esteem).

Educational theories represent themselves, or are taken as representing themselves, in certain ways. Most of these ways are disguises which have to be understood as such. Generally speaking, they appear as part of "philosophies," outlooks on life, or ideologies which somehow incorporate an educational theory, or to which an educational theory is added as a sort of appendix. It is remarkable, in fact, how few philosophers have regarded education as an enterprise in its own right with it own values, objectives, and procedures. 2 The commonest disguise for such ideologies is as a set of empirical truths about human nature, child development, the nature of learning, motivation, and the like. But they may also be presented as conceptual truths or necessary (non-empirical) truths (as 
perhaps in the work of R.S. Peters and other conceptual analysts). As mentioned earlier, we know how to deal with and verify discourse of this kind, so that to this extent educational theories are methodologically non-problematic. We can conduct empirical enquiries more rigorously, and conceptual ones more carefully, in order to evaluate these elements in the theories. It is rather the nature of what remains in such theories that is problematic.

There is a temptation at this point to feel that they ought to remain problematic, or vague, or at least not be too quickly classified or straightjacketed into some recognizable and methodologically manageable form of discourse. Can they not be left in the (admittedly but perhaps rightly) vague or obscure calegory of "general ideas," "theories," "ideologies," "pictures of education," or whatever? Could these not still be "fruitful," "interesting," "insightful" (as well as culturally influential, which they certainly are)? We have some sympathy with this feeling, but the question still presses upon us: what sort of "fruitfulness" or "insight" are we to expect from them? how we are judge them? We have still to remember that not all such "general ideas" are necessarily useful or desirable (remember the Nazis again): they may be deceptive, misguided and, in some cases, pure lunacy.

Nor is it sufficient to say that some of these theories have "stood the test of time," as if their abiding influence-the fact that people still read them and apparently "get something out of them"-were somehow in itself a justification of their value. Many religions, not to mention other general outlooks on the world or on human life such as Marxism or Freudianism, have in this sense stood the test of time, but it is still an open question whether "there is something in them" and, if so, just what it is. It would be perfectly possible to regard much or all of them as a set of fantasies or rationalizations. We meet here yet again the pressing point that we feel, and ought to feel, a certain methodological or procedural impotence in the face of such things. In virtue of what criteria do we dismiss Nazi philosophy, for instance, as valueless and accept Marx and Freud as valuable? Are we not simply warmed by some worldpictures and chilled or horrified by others? Are we not simply acting out our own fantasies in intellectualized or rationalized forms, when we write or read or criticize them? Are we (to put it severely) behaving responsibly in spending our time thus? The position is uncomfortably like that of medieval pseudo-science in which, without a proper methodology, scientists were reduced simply to picking among the fantasies about the origin and nature of the world on the basis of what happened to appeal to them. To finalize the point less theatrically: reason cannot get a grip on any form of discourse unless we have some idea about the criteria which we are to apply to it, or the standards of reason which it is supposed to satisfy.

I(2), Spring, 1988 
We are tempted to stop at this point because it seems to us more important that these basic questions should be faced squarely (as at present they are not) than that any particular answers should be given. Clearly there are a great many possible answers, and what follows is no more than a first attempt to sketch out some of them. Here we have been strongly influenced by those philosophers (in particular, Wisdom following Wittgenstein) who, whilst deploying analytic rigour, are nevertheless sympathetic to forms of discourse which do not fit neatly into the conceptual/empirical dichotomy.

Perhaps the most interesting suggestion is the possibility of turning our negative criticisms into something positive. We are to say something like

Yes, of course it is true that much of our theorizing and our general ideas is likely to be fantasy, or mixed up in fantasy: particularly and predictably in areas like religion, education, politics, and morality. But it is important that we should see these fantasy-elements clearly and, for that purpose, we need to have them fully and attractively explicated and articulated. Educational theories are such articulations. For instance, if we have strong feelings, no doubt derived from unconscious attitudes about authority, guilt, adult oppression and the other standard dramatis personae of psychiatry about the freedom of the child, then it helps to have these articulated in the way that Rousseau (or perhaps even Dewey) articulates them. We need to see them in full flower, as it were, in order to perceive and catch the emotional features which generate them. Only then will we have a proper chance of making rational judgments because only then will the material be fully available to us.

The attraction of this idea is that it gives some sort of raison d'etre to almost any popular "general idea." Its popularity shows that it contains elements which, just because they have an appeal, need at least to be looked at and analyzed. In just such a way a therapist needs the patient to explicate his fantasies-which may well take the shape of some public ideology-because he and the patient cannot get to work on them before fully grasping what they are. Clearly, it would be useful to determine exactly what the Nazis (or their unconscious minds) actually were trying to do (to put the matter in the most positive light we can think of). Even in such cases, there may be valid human feelings trying to express themselves to which justice must somehow be done (though preferably not in the way the Nazis tried to do it). 
This is, however, to take educational theories seriously only as sets of symptoms, as pathologies (and that must be, in some degree, the right way to lake them). A reply might be along the lines of

Yes, if people really must project their emotions into these highly-articulated ideologies, and insist on clinging to them, then of course as reasonable critics (as therapists, in effect) we have to understand and deal with them-at least until the patient (theorist) can give them up. But if - as surely we can-we reach the stage of not needing to make such projections, and come to understand that the true subject-matter is not some externalized theory but the deep tangle of emotions inside us, is there any place left for the projections? Will they not simply be given up (as of course happens in successful therapy) in favour of a more piecemeal, less theory-laden, analysis of the emotions themselves (and no doubt their early history in our minds)? Would we not abandon this large-scale quasiphilosophical acting-out in favour of individual therapy? Is that not, in fact, just how a sensible person would try to deal with the Nazis, trying to make them sufficiently sane or secure to abandon these rationalizations?

The answer to this, as we see it, must be in general an affirmative one. But that judgement represents the rather pessimistic viewpoint that a very large proportion of educational theory (and, come to that, educational practice) is in fact fantasy and requires to be abandoned. Some of it, however, may contain genuine insights, perhaps something like wisdom. Thus, in our parallel, a patient who has various fantasies about women, and casts them in the form of theories, "God has ordained the place of women to be such-andsuch," etc.), will, if successful in his therapy, abandon these, but he will not therefore cease to have views about women, insights into their nature, rational feelings and responses to them. The question really is how far these require any kind of general or theoretical form. It is initially plausible to say, we think, that (because the device of projection and theory is so tempting) there will be a good deal less "theory" and a good deal more attention to the particular. But that does not mean that there is no place for generality.

Perhaps most of the kind of work that educational theory (when stripped both of its conceptual and empirical truths, and of its disguises) ought to be doing could be better done by more piecemeal procedures: for instance, by the use of fictional literature, or case studies. Wisdom and insight-whatever indeed these are-are, surely, gained by experience and aids to experience, amongst which good fic- 
tion is a well-qualified candidate. It is perhaps undeniable that someone who has profited by his own and other people's experience in this way will, in fact, end up with some sort of general (if largely unconscious) views about life and its various enterprises-education, personal relationships and others, which particularly require the general virtues of clarity and sanity rather than technical or empirical truths. He will come to think, for instance, that love rather than fame is important, or that personal affection is more worth having than worldly success, or that a genuine attachment to intellectual pursuits must take priority over the passing of examinations, or whatever. But nearly all the weight, so to speak, or the value or force of such generalizations will be carried by the particular cases and experiences he has had. Otherwise, they are empty truisms that may be interpreted in quite the wrong ways. (There is a parallel here with Wittgenstein's view of philosophy as the assemblage of reminders, not as generating a set of new theories or sophisticated truths.)

Of course, that is not to deny that-in a more theoretical sort of way-obscure "general ideas" or theories may not lead to both conceptual and empirical truths which may be, in some sharper sense, new to us. Thus Marx and Freud may, in the course of time, be seen to point us to new findings in economics, history, or psychology. No doubt such writing ought to be held in suspension, as it were, rather than dismissed too quickly Nearly all empirical advances have benefited from this approach rather than from applying logical distinctions too swiftly. Even natural scientists tend to start with some general idea about nature and only later cast this into a shape which will lend itself to experiment and observation. How far that is true of educational theory seems doubtful. One's intuition-it is no more than that-is that such theory is much more concerned with value and the perception of human nature than with a first attempt at some kind of empirical hypothesis. (The same would be true of other "general ideas," such as religion. It is surely not religion as such that leads to scientific discovery, but it may point to or contain insights about the human condition.)

If this is in fact the case with educational theory-perhaps all theory that deals deeply with human nature rather than physical objects-then all the stress has to be put on procedural criteria. Instead of expecting certain truths to inhere in the discourse itself -instead of asking what is supposed to be true about Rousseau or Dewey or whoever-we have rather to work on ourselves in relation to the discourse (again, as in competent psychotherapy). Such procedural criteria are hard to state. They would, necessarily, in- 
clude our willingness and ability to examine concepts analytically and judge the clarity of the discourse (not because conceptual analysis is a respectable procedure for philosophy, but for the procedural reason that clarity and understanding come partly through such analysis). By developing a nose for incoherence and a taste for making clear and interesting distinctions, we can release ourselves from an overall fantasy which may exist only because its incoherence is unexplored. Our procedures would also include looking carefully at our own emotional reactions to the discourse and the background (often unconscious) reasons or causes of such reactions. Other procedural criteria, perhaps obvious in that we constantly pay lip-service to them but nevertheless crucially important, would include such things as the ability and willingness to attend seriously to other points of view, to answer rather than avoid questions, not to take arguments ad hominem or feel threatened by criticism (or at least to take time off to understand why we feel threatened), to be able to argue opposing viewpoints inside our own heads rather than just warming uncritically to some general idea, and in general to follow the Socratic (or the therapeutic) model in our handling of such discourse. In this light, the initial question, "Do we need theories of education?" can be seen to have no unequivocal answer. As usual in philosophy, all the important points lie in what is to count or be seen as theory. On our account, such discourse can be useful as subject-matter, a springboard for useful discussion, provided we are not tempted to agree or disagree with the theory as a whole, or even to react for or against it in some overall quasi-emotional way, but are mature enough to apply the procedural criteria mentioned (too briefly) above. In just such a way a philosophical text of any kind can be a useful start for discussion, if only to focus our attention, but could not be taken as representing some kind of ideology which we have to accept or reject. That, however, is largely a pedagogic point. If and when we can grasp and apply the procedural criteria in their own right, the presence or absence of a text may be irrelevant. Similarly some therapists may find it useful to write books of a general nature about the importance of love as against possessions or whatever (the work of Fromm comes to mind here). Initially, these may focus the patient's attention on something which bears some relation to his real problems. But the real work comes later when we are able to see those problems for what they are, stripped of general or metaphysical disguises.

A penultimate point about which we have so far said nothing: who are the "we" who need or do not need all this theory? One writes articles like this, perhaps without sufficient focus, for "reasonable people" in general, or for educational philosophers, or teacher-educators, or whoever. But the truth is that some people-not necessarily paid-up professional philosophers or I(2), Spring, 1988 
psychotherapists - are more sophisticated (perhaps more reasonable in some suitably wide or deep sense of the term) than others and the question of the need or use of educational theory must receive somewhat different answers depending on who is using it for whatever purposes. Thus, at one end of the scale, it may be that one person can only retain some degree of personal integration, or sanity, or sense of meaning in life if he dedicates himself wholeheartedly to some theory of this kind (probably not just an educational theory) and that represents some at least ad hoc or pro tempore sort of need. At the other end, more sophisticated and mature personalities or intellects will perhaps not themselves need much of such theory, but may find it useful as pedagogic subject-matter in dealing with patients or clients - if only because certain theories may be socially fashionable, and one has to start "where the learner is." These are, of course, tactical or pedagogical questions. Philosophers, whom we have had clearly if not exclusively in mind, have to decide, for instance, when they are writing for-one may say, trying to cure-the unsophisticated layman, and when they are writing for colleagues who are more sophisticated. Their use of educational theory may depend on the audience. It must be borne in mind, however, that the tactical use of philosophy would become very rapidly corrupted or trivial if it were not based on and derived from some purer or more sophisticated form of philosophy, just as therapists require some kind of abstract, non-tactical view of fantasy, projection, and so forth before they can deal effectively with individual patients. Philosophers will be worthless if they see themselves only as a service industry, their work valuable only when it does not aspire to high levels of sophistication. At that level, we have been arguing, what passes for educational theory may have a comparatively small or short-lived part to play.

Finally, we would stress that there is much to be said (which we cannot say here) about the particular bewitchments, doctrinaire ideas, or mental postures which lie behind our basic question, not about the fantasies we may have about the particular contents of theory, but those we may have about the idea of theory itself. Everyone, we believe (including the present authors), suffers from these. It is, for instance, reasonably clear that the positivists, who were criticized earlier for declaring moral discourse as meaningless, were so suffering. The mistake, like most major philosophical mistakes, was so obviously wrong that one's interest naturally focuses on why in the world anyone wants to say such things. What is the (behaviouristic? materialistic? science-dominated?) world-picture or mental bewitchment that generates such views. Much more common, however, is the fantasy that to be respectable intellectually or academically one must rely on "theory" in something like, or at least 
redolent of, the-entirely clear and domesticated-sense in which we use the term in natural science. Natural science, which is the big success story in recent cultural history, exercises an immensely bewitching effect. Here, as so often, our mere retention of the word "theory" may betoken an unconscious desire to return to a viewpoint which analytic philosophy (perhaps too ferociously) tried to dispel: the viewpoint that world-pictures, "philosophies," or "theories" ought to at least be like science in that we need a high level of generality and some all-encompassing view about the world or about particular enterprises, like education, within the world. There is absolutely no reason to believe this-or even to believe that sociology and psychology, insofar as they represent themselves in this way, are intellectually respectable enterprises. Our approach to education perhaps ought to take its cue from the study of history, where (among reputable historians at least) there is no question of producing laws, large generalizations, or theories at all. Historians simply shed light on particular cases, connecting one case with another (as one connects one personal experience with another), but not connecting them in the way that the natural scientist does. When E.M. Forster in Howard's End produced the apothegm "Only connect," he was not thinking of some general theory of human nature.

\section{Notes}

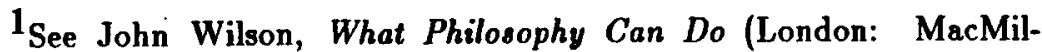
lan, 1987.)

${ }^{2}$ See John Wilson, Preface to the Philosophy of Education (London: Routledge Kegan and Paul, 1979). 